\title{
A abordagem da variação linguística no programa Inglês sem Fronteiras: da teoria à prática
}

\section{El enfoque de la variación lingüística en el programa Inglés sin Fronteras: de la teoría a la práctica}

\author{
The approach to linguistic variation in the English without \\ Borders program: from theory to practice
}

Matheus de Almeida Barbosa ${ }^{1}$

\begin{abstract}
RESUMO: O inglês apresenta variações de ordem geográficas, situacionais e sociais. No contexto de ensino de inglês como língua estrangeira, este artigo objetiva investigar os relatos do ensino da variação linguística em aulas do Programa Inglês Sem Fronteiras (IsF), na Universidade Federal da Paraíba (UFPB). Trata-se de um estudo de caráter exploratório, com uso de entrevista semi-estruturada (MANZINI, 2003), a fim de coletar os dados para responder a questão que norteia esta pesquisa. Partimos de uma busca por uma visão de língua que comporte os estudos sobre a variação linguística, bem como de uma abordagem de ensino de línguas que inclua 0 estudo sobre variações nos seus pressupostos. Deste modo, tomando por base os estudos da Sociolinguística e a Abordagem Comunicativa, a partir das pesquisas realizadas por Labov (2008) e Hymes (1972), enfatizamos a importância do ensino da variação nas aulas de inglês. Os resultados apontam que as professoras do IsF conhecem a variação linguística e consideram importante ensinar diferentes variantes em aula. Além disso, buscam mostrar aos alunos que existem diferenças na forma como a língua é utilizada e estas diferenças são importantes para um uso contextual da língua.
\end{abstract}

PALAVRAS-CHAVE: Variação linguística. Inglês como Língua estrangeira. Inglês sem fronteiras.

RESUMEN: El inglés presenta variaciones de orden geográficas, situacionales y sociales. En el contexto de la enseñanza de inglés como lengua extranjera, este artículo tiene como objetivo investigar los relatos de la enseñanza de la variación lingüística en clases del Programa Inglés Sin Fronteras (ISF), en la Universidad Federal de Paraíba (UFPB). Se trata de un estudio de carácter exploratorio, con uso de entrevista semiestructurada (MANZINI, 2003), a fin de recoger los datos para responder a la cuestión que orienta esta investigación. Partimos de una búsqueda por

\footnotetext{
${ }^{1}$ Mestre em Linguística pelo Proling UFPB, e atualmente doutorando em Linguística pelo mesmo programa.
} 
una visión de lengua que comporte los estudios sobre la variación lingüística, así como de un enfoque de enseñanza de lenguas que incluya el estudio sobre variaciones en sus presupuestos. De este modo, tomando como base los estudios de la Sociolingüística y el Enfoque Comunicativo, a partir de las investigaciones realizadas por Labov (2008) y Hymes (1972), enfatizamos la importancia de la enseñanza de la variación en las clases de inglés. Los resultados apuntan que las profesoras del IsF conocen la variación lingüística y consideran importante enseñar diferentes variantes en clase. Además, buscan mostrar a los alumnos que existen diferencias en la forma en que se utiliza la lengua y estas diferencias son importantes para un uso contextual de la lengua.

PLABRAS CLAVE: Variación Lingüística. Inglés como Lengua Estrajera. Inglés sin fronteras.

ABSTRACT: English shows variations regarding geographical distribution, situational context and social status. Considering the context of Teaching English as a Foreign Language, this paper aims to investigate the testimonies of how linguistic variation is approached in English language classes in the Brazilian Government program English Without Borders (EwB), at the Federal University of Paraíba (UFPB). It is an exploratory study, which makes use of a semi-structured interview script (MANZINI, 2003), in order to collect the data needed to answer the question that guides this research. We started searching for a concept of language that incorporates the study of linguistic variation, as well as an approach to foreign language teaching that includes the study of such variations among its assumptions. Thus, based on the study of Sociolinguistics and the Communicative Approach, based on researches made by Labov (2008) and Hymes (1972), we emphasize the importance of teaching linguistic variation in the classes. The results show that the teachers of the EwB program have demonstrated to know about linguistic variation and consider it important to teach different variants in the classroom. Moreover, they try to show their students that differences occur in how it is used and that such differences are important to a contextual use of language.

KEYWORDS: Linguistic variation. English as a foreign Language. English without borders.

\section{Introdução}

Ao entrarmos em contato com falantes de nossa língua materna, podemos perceber como são numerosas as variações que podem ocorrer na fala das mesmas, sem que isto, necessariamente, cause dificuldades de comunicação para ambas as partes. Ao estudarmos uma segunda língua, no entanto, consideramos que, para desenvolvermos de modo holístico nossa competência comunicativa faz-se necessário, termos conhecimento acerca 
dessas variações e também saber lidar com elas naturalmente, adequando nossa fala às situações de uso nas quais estamos inseridos.

O estudo do inglês como segunda língua leva-nos a observar a frequência com que essas variações ocorrem, uma vez que, por ser a terceira língua mais falada no mundo, ela sofre influência de várias outras, bem como se modifica internamente ao longo do tempo. Com isto, surge a questão: as variações linguísticas são efetivamente tratadas no ensino do inglês como segunda língua? Mais especificamente, dentro do programa Inglês sem fronteiras, como são tratadas estas questões de ensino de variação? Qual a percepção dos professores do referido programa sobre este conteúdo?

Para refletirmos sobre essa questão, lançamos mão de um estudo de caráter exploratório, a partir do qual faremos uso de um roteiro de entrevista semi-estruturada (MANZINI, 2003), a fim de investigar como se dá o ensino da variação linguística em aulas de língua inglesa ministradas por duas (02) professoras do Programa Inglês sem Fronteiras, desenvolvido na Universidade Federal da Paraíba (UFPB). Este trabalho foi aprovado pelo Comitê de Ética e Pesquisa da Universidade Federal da Paraíba, com protocolo CAAE 53604916.7.0000.5188.

Inicialmente, buscaremos caracterizar a língua inglesa no cenário atual internacional, como língua materna em alguns países ou língua estrangeira em outros, o que a coloca em terceiro lugar no ranking das línguas (MULLER, 2014) mais faladas do mundo. Em seguida, abordaremos a concepção de língua a partir do Estruturalismo Saussureano e do Gerativismo Chomskyano, e assim evidenciaremos que, muitas vezes, as correntes linguísticas não dão conta de englobar o fenômeno da variação linguística. Por outro lado, há correntes, como a Sociolinguística, que podem contribuir para ampliar a concepção de língua e, assim, subsidiar uma prática eficaz de ensino da língua inglesa. 
Acerca da variação linguística, apresentaremos os diferentes tipos de variação linguística: variação diatópica, variação diafásica e variação diastrática. Além dessas, também falaremos brevemente sobre a importância de se entender sobre os dialetos e quais os fatores que diferenciam dialetos de línguas.

Para trazer a variação linguística para a sala de aula de língua inglesa, discutiremos muito além do ensino de língua através do ensino de regras oriundas de uma gramática normativa, visão esta atrelada a uma língua que é imutável, estática e inabalável em suas regras. Nesse momento, aproveitaremos para discutir o conceito de competência comunicativa e como esta deu origem a uma forma de ensino de línguas chamada de Abordagem Comunicativa. Esta abordagem explora, entre outras coisas, a competência sociolinguística do falante como parte essencial para que uma língua seja efetivamente estudada.

Na sequência, ainda será possível tratar de como a variação linguística é concebida dentro da academia, no que diz respeito à formação de futuros professores de língua inglesa.

Na seção seguinte, apresentaremos dados do Programa Inglês sem Fronteiras, desde sua criação até seus objetivos atuais dentro de um programa maior, intitulado Idiomas sem Fronteiras. Posterior a essa apresentação, faremos uma análise das entrevistas concedidas por duas professoras do Núcleo Inglês sem Fronteiras da UFPB. Finalmente, concluiremos com uma reflexão buscando integrar os conceitos discutidos ao longo deste artigo.

\section{Variação linguística: da teoria à prática}

Atualmente, a língua inglesa se configura como a terceira língua mais falada no mundo, com mais de quatrocentos e vinte sete milhões de falantes 
nativos e (estimados) mais de novecentos e cinquenta milhões de falantes não nativos em todo o mundo, ficando atrás apenas do mandarim e do espanhol.

No entanto, apesar de ficar somente na terceira posição neste ranking, a penetração a nível global deste idioma é altíssima, uma vez que é língua nativa de poucos países (Grã-Bretanha, Irlanda, Estados Unidos da América, Canadá, Austrália, Nova Zelândia e alguns países do Caribe), mas é utilizada como língua oficial em outros 57 países nos quais seus habitantes a utilizam como primeira língua. Estima-se que, na Europa, cerca de $85 \%$ dos suecos, $83 \%$ dos dinamarqueses, $79 \%$ dos holandeses e mais de $50 \%$ dos finlandeses, belgas e alemães podem conversar em inglês confortavelmente (MULLER, 2014).

No Brasil, o número de pessoas estudando a língua inglesa ultrapassa os vinte milhões, somando aí crianças, adolescentes e adultos (FRANÇA, 2001). Desta forma, podemos perguntar: a língua inglesa é falada da mesma forma por todos os seus falantes? Será que durante o aprendizado de uma língua estrangeira, os alunos são expostos a diferentes variantes da língua?

Ao levarmos em consideração as proposições de Saussure (2012) acerca do que ele considerava língua, veremos que esse linguísta faz sua descrição acerca do objeto de estudo da linguística se utilizando de analogias e dicotomias. A primeira dicotomia que Saussure procura estabelecer, e que serve de ponto de partida para todo seu estudo, é a dicotomia entre língua e fala. Para o autor, língua e fala são partes indissociáveis de uma mesma moeda, apesar de terem naturezas diferentes. A língua seria a parte social, compartilhada, e que seria independente do indivíduo, pois não caberia a este modificar a língua. Por outro lado, a fala seria um ato completamente individual em sua essência, pois partiria da vontade e inteligência dos indivíduos. Entendemos, com Saussure, que "língua é um sistema de signos que exprimem ideias" (SAUSSURE, 2012, p. 47). 
Para dar mais clareza ao objeto de estudo "língua", faz-se pertinente considerar as características a ele associadas. Para Saussure (2012, p. 51), "a língua existe na coletividade [...] mais ou menos como um dicionário cujos exemplares, todos idênticos, fossem repartidos entre os indivíduos". Ora, visto por este aspecto, podemos nos questionar se realmente a língua que falamos no nosso dia a dia corresponde a esta coletividade de dicionários idênticos, compartilhados por todos os falantes da língua. O próprio Saussure $(2012$, p. 51) assume que "é a fala que faz evoluir a língua: são as impressões recebidas ao ouvir os outros que modificam nossos hábitos linguísticos". Ou seja, ao assumir que a fala faz com que a língua evolua, Saussure (2012) concorda com o fato de que as línguas mudam, no entanto, ao assumir que a língua é um sistema homogêneo entre todos os falantes, não dá subsídios para que ocorra variação entre as falas dos indivíduos, que levariam à mudança linguística.

Outra forma de se entender o que seria língua, pode ser visto a partir dos estudos da Gramática Gerativa (GG), linha de pensamento iniciada em meados de 1950 por Noam Chomsky, linguista norte-americano. Chomsky (1994), através da GG, propõe duas visões de língua chamadas língua-E e língua-I. Antes, no entanto, de se estabelecer diferenças entre as duas, é preciso entender de onde elas surgem.

Para a GG, a princípio haveria uma propriedade existente na mente de todas as pessoas que permitiria que uma língua fosse adquirida em condições de experiência pura e uniforme. Essa propriedade é caracterizada como a Gramática Universal (GU). Ao assumir essa característica da GU, que é comum a toda a espécie, a teoria gerativista também assume a existência de um estado inicial de língua $\left(E_{0}\right)$. Todo o conhecimento de língua deriva desse estado inicial, que converte a experiência a um estado estável $\left(\mathrm{E}_{\mathrm{E}}\right)$ de língua, chamado língua-I. Já a língua- $E$, também chamada língua externa, é um construto independente das propriedades da mente/cérebro. A língua-E se 
assemelharia aos atos linguísticos reais ou potenciais, que podem ser analisados em termos de fonemas e morfemas, e que foi o objeto de estudo num panorama anterior, trabalhado pelo estruturalismo americano. Chomsky (1994) é categórico em afirmar que dentro da teoria que propõe a língua-E pode haver várias definições, ou ainda não ter definição, uma vez que não desempenha papel nenhum na teoria da linguagem. Na teoria da linguagem proposta por Chomsky, gramática seria uma teoria de língua-I, que seria o objeto a ser estudado. A língua-I, ou língua interna, é algo que existe na mente de uma pessoa que conhece a língua e é utilizada pelo falante-ouvinte. Desta forma, a visão de língua que a GG se propõe a estudar, a língua-I, não carregaria consigo os fatores sociais que são inerentes a uma questão de diversidade dentro de uma própria língua, pois seria muito homogênea; e a língua- $E$, que carregaria a potencialidade de se assemelhar aos atos linguísticos realizados, é categoricamente retirada do escopo de estudo da língua proposto por Chomsky.

Outra concepção de língua é a da Sociolinguística, que tenta relacionar a linguística com a sociedade. Rodrigues (2005) faz uma trajetória histórica acerca do surgimento da Sociolinguística, desde meados de 1960. Desde seu início, essa corrente já dizia que uma visão homogênea da língua que não incorpore variantes não dá conta do "leque de associações das línguas com a estrutura social" (RODRIGUES, 2005, p. 15).

No campo da Sociolinguística, esse autor ainda levanta dois conceitos que têm grande importância nos estudos sociolinguísticos: variante e variável. Variantes linguísticas seriam as diversas formas de se dizer uma mesma coisa num contexto, e variável linguística seria o conjunto de variantes.

Sobre a variação linguística, podemos defini-la, em conformidade com Beline (2012, p. 122), como "[...] um conjunto de duas ou mais variantes. Estas por sua vez, são diferentes formas linguísticas que veiculam um mesmo 
sentido". Para esse autor, há três possíveis tipos de variação. A primeira seria a variação diatópica, compreendida como variações que levam em consideração aspectos geográficos. As variações diafásicas ocorrem em relação aos diferentes estilos de língua, variando entre os mais formais e os mais informais, de acordo com a situação de uso. Por fim, as variações diastráticas, que levam em conta aspectos socioeconômicos do falante, como sexo, idade, classe social, etnia entre outros. Uma das formas de se verificar essas variações é através dos estudos dos diferentes dialetos. Chomsky (1994, p. 35), ao analisar os conceitos de língua a partir do senso comum, levanta um aspecto de dimensão sociopolítica importante, especialmente quando diferencia língua de dialeto e diz que "uma língua é um dialecto com um exército e com uma marinha", ideia atribuída ao sociolinguista Max Weinreich. Lyons é bem sucedido ao falar sobre esta diferença:

Por exemplo, o mandarim e o cantonês são chamados de dialetos do chinês, mas são mais diferentes um do outro do que, digamos, o dinamarquês do norueguês, ou ainda mais marcadamente, o holandês do flamengo ou do africâner, que frequentemente se descrevem como línguas estanques (LYONS, 1987, p. 18-19).

A partir dessa citação de Lyons (1987), podemos perceber que a diferença entre língua e dialeto pode ser considerada muito mais uma questão política do que uma questão linguística. Algumas das línguas citadas por esse autor possuem mais semelhança e são melhores intercompreensíveis entre si, do que dois dialetos do mesmo idioma, como, por exemplo, o mandarim e o cantonês, dialetos do chinês.

Em relação ao ensino de idiomas, alguns métodos e abordagens são de interesse quando se trata de estudar a variação linguística. Durante muito tempo, o ensino de línguas estrangeiras focou no estudo da norma culta gramatical, e os momentos de uso prático da língua estavam sempre submetidos à prática dessas regras gramaticais. Essa forma de trabalhar no 
ensino de idiomas ficou conhecida como método da gramática-tradução. É possível ver que, por priorizar uma determinada forma da língua, as outras deveriam então ser consideradas inferiores, o que não abria espaço para o estudo de variação linguística.

Uma das principais abordagens que surgiram em oposição a este método veio do desenvolvimento da noção de competência comunicativa. Este termo surgiu por volta da década de 1970, em oposição à caracterização de competência linguística, proposta por Chomsky, e tentava representar o uso da língua dentro de um contexto social. É preciso salientar que o termo competência comunicativa não surgiu no contexto de ensino de línguas, mas nos estudos de língua como comportamento social. De toda forma, a noção de competência comunicativa culminou com o desenvolvimento de uma abordagem de ensino de idiomas, a Abordagem Comunicativa, que visa desenvolver a competência comunicativa através do desenvolvimento de quatro outras competências: gramatical (ou linguística), discursiva, estratégica e sociolinguística (SAVIGNON, 2001). Ora, se esta abordagem se preocupa em desenvolver a competência sociolinguística do aprendiz, também deve se preocupar em tratar da variação linguística. Não somente isto, mas os livros didáticos e instituições de ensino de língua estrangeira que se prontificam a trabalhar com a Abordagem Comunicativa deveriam levar em consideração questões relativas ao ensino de variação linguística, afinal, o contexto em que o aluno entrará em contato com a língua, em sua forma real, pode vir com variantes diferentes daquelas a que ele foi exposto durante seus estudos.

Este ponto de vista é ampliado por Bortoni-Ricardo (2005, p. 15), quando fala que:

A escola não pode ignorar as diferenças sociolinguísticas. Os professores e, por meio deles, os alunos têm que estar bem conscientes de que existem duas ou mais maneiras de dizer a mesma coisa. E mais, que essas formas alternativas servem a propósitos comunicativos distintos e são recebidas de maneira diferenciada pela 
sociedade. Algumas conferem prestígio ao falante, aumentando-lhe a credibilidade e o poder de persuasão; outras contribuem para formarIhe uma imagem negativa, diminuindo-lhe as oportunidades.

É possível ver, deste modo, a importância de se estudar as variações dentro da sala de aula de língua estrangeira, visto que o uso de uma variante em detrimento de outra pode causar estranheza e até mesmo ser motivo para que, sem ter conhecimento, o falante crie, em seu interlocutor, uma imagem negativa.

Uma proposta para se analisar como essa variação acontece em materiais didáticos utilizados em escolas para o ensino de inglês foi apresentada por Rodrigues (2005). Em seu estudo, o autor selecionou dois livros didáticos e seus respectivos livros do professor, e procurou ver como os diferentes tipos de variação poderiam ocorrer nas seções dos livros que trabalham compreensão da leitura, vocabulário e gramática. No primeiro livro, o autor não encontrou nenhuma variação dialetal na parte de compreensão da leitura, bem como pouca variação no que tange aos níveis de formalidade.

Ainda em relação ao primeiro livro, sobre a seção de vocabulário, o autor foi capaz de encontrar algumas variantes que dariam conta de uma variação diatópica, no entanto, a falta de explicação sobre essas variáveis deixariam o aluno a mercê de uma possível explicitação por parte do professor, uma vez que essas variantes eram explicadas com mais detalhes no livro do professor. Para finalizar o primeiro livro, na parte de gramática, o autor também conseguiu encontrar ocorrência de variantes, neste caso, de variação diafásica, que eram mostradas aos alunos como sendo equivalentes e intercambiáveis entre si, mas cuja explicação era inexistente. Sobre o segundo livro analisado, na parte que trabalhava com compreensão da leitura, o autor não localizou registros de variação dialetal, mas sim de diferenças de gêneros textuais. Rodrigues (2005) pôde localizar, dentro dos textos, exemplos de variação diafásica, porém estes não são explicitamente explicados no livro do aluno. Na 
seção seguinte, de vocabulário, o autor encontra diversas atividades que trabalham com variantes, a exemplo de exercícios com gírias. No entanto, não há explicação prévia para estas, o que faz com que os alunos fiquem dependentes da correção por parte do professor para saber se estão corretos. Por fim, na seção sobre gramática, o autor enfatiza que a forma como o livro trabalha com gramática é através da indução², o que faz com que a gramática seja vista de forma menos presa, com ênfase no uso, o que seria um indicativo do nível de formalidade, porém, mais uma vez, sem trazer as devidas explicações. Por fim, o autor levanta a necessidade da escolha de materiais didáticos que trabalhem a variação linguística sob diferentes perspectivas, e utilizem várias abordagens para melhor compreensão por parte dos alunos.

Francescon, Senefonte e Baronas (2013) buscaram investigar como a variação linguística é vista nos documentos oficiais para o ensino de língua estrangeira no Brasil, e também em dois livros didáticos adotados na rede pública de ensino do Paraná. Sobre os documentos oficiais, eles verificaram que tanto os documentos nacionais quanto os estaduais direcionam o ensino de línguas, seja materna ou estrangeira, para lidar com diferentes tipos de situações comunicativas, bem como para que o aluno tenha acesso a uma miríade de variedades linguísticas, permitindo a escolha da variedade mais adequada ao contexto de uso no qual o aluno esteja inserido. Isto é reforçado nos parâmetros para adoção dos materiais didáticos, que afirma que os textos utilizados nos livros didáticos devem ser representativos de diferentes comunidades de fala, bem como devem apresentar atividades de compreensão

\footnotetext{
${ }^{2} \mathrm{~A}$ indução, utilizada em aulas de língua estrangeira, ocorre quando um determinado tópico é primeiramente trabalhado em sala de aula, a partir de seu uso, e somente após os alunos conseguirem lidar com o item trabalhado, eles irão refletir sobre as regras que estão por trás desse uso. Esta forma está em oposição à dedução, em que, primeiramente, os alunos precisam ter contato com as regras de um tópico e, somente quando internalizam essas regras, partem para usar o que foi aprendido. Para mais detalhes, um ponto de partida pode ser o capítulo Form-focused Instruction, do livro de Douglas Brown (2001), Teaching by Principles.
} 
auditiva que deem acesso às diferenças no tocante à pronúncia e à prosódia. Desta forma, é possível perceber que, oficialmente, o ensino de língua estrangeira, mais especificamente do inglês, deveria contemplar o estudo das variações linguísticas sob diferentes modalidades. Em relação aos materiais didáticos analisados, apesar de os autores conseguirem encontrar exemplos de variação neles, por menores que sejam não há uma proposta por parte do próprio material a analisar as variações, o que revela certa negligência acerca da abordagem da variação linguística nas aulas de língua inglesa, limitando o desenvolvimento da competência comunicativa do aluno.

Estudando como alunos do ensino médio reconheciam algumas palavras em inglês, Falcão e Silva (2013) apresentaram a eles imagens contendo duas formas distintas da língua inglesa, variantes, americana e britânica, que poderiam ser relacionadas com a imagem em questão, ou ainda palavras que se relacionavam ao mesmo referente, porém, com pronúncias distintas. É interessante perceber, no relato dos autores, que os alunos demonstraram surpresa, curiosidade e interesse em conhecer como poderiam dizer a mesma coisa usando duas variantes diferentes. Pelo relato, também se pode perceber que, até então, tais alunos deveriam estar sendo expostos a uma única variante dessas palavras, o que retoma a discussão sobre uma forma ideal de língua para ser ensinada. Esta forma, de uma variante sendo considerada a forma ideal, não é aceita atualmente na linguística.

Cientes de que as práticas desenvolvidas pelos professores, na sala de aula, são responsáveis pelo sucesso do aluno, Alves e Battisti (2014) desenvolveram um projeto com os alunos de graduação do curso de LetrasInglês da Universidade Federal do Rio Grande do Sul (UFRGS), no qual tentaram aproximar os conhecimentos linguísticos dos alunos dos conhecimentos teóricos em sociolinguística. No referido projeto, durante a disciplina curricular de Língua Inglesa $V$, foi introduzida a noção de variação 
linguística na língua inglesa, em módulo cujo objetivo era discutir conceitos da teoria sociolinguística aplicados na língua inglesa. Através dessa intervenção, os autores puderam verificar, entre outras coisas, quais concepções de língua os alunos haviam internalizado, assim como também constataram que os alunos do curso, apesar de terem conhecimento teórico sobre sociolinguística, não possuíam conhecimento prático abrangente nos vários tipos de variação linguística. Outro ponto interessante de se observar foi que, mesmo tendo consciência de que um falante nativo se utiliza de variantes no seu dia a dia, os alunos relataram que um falante não nativo precisa confinar-se à norma culta, reproduzindo a ideia de uma língua ideal, preconizada nos manuais. Essa concepção dos alunos levou os autores a reconhecerem a problemática existente naquela formação dos professores de Letras-Inglês, no entanto, o trabalho realizado a partir do projeto certamente contribuirá para modificar tal concepção.

\section{O Programa Inglês Sem Fronteiras: Contextualizando}

O Programa Inglês sem Fronteiras (doravante IsF) foi instituído através da Portaria no 1466, de 18 de dezembro de 2012, do Ministério da Educação, levando em consideração o Decreto no 7642, de 13 de dezembro de 2011. Em seu artigo 11, inciso III, o referido decreto dispõe sobre uma das atribuições do Programa Ciência sem Fronteiras: "promover o ensino e a aprendizagem de idiomas estrangeiros." (BRASIL, 2012).

Na Portaria que institui o IsF são traçados objetivos que o programa deve buscar cumprir. O objetivo principal seria preparar os alunos de graduação para se submeterem aos testes de proficiência exigidos pelas universidades anglófonas para 0 ingresso nas referidas universidades. Para atingir este objetivo principal, outros cinco são traçados. O primeiro, dar capacitação em língua inglesa nas modalidades virtual e presencial, dando oportunidades de 
experiências voltadas para o aprimoramento em áreas prioritárias e estratégicas para o Brasil. O segundo, ampliar a participação e mobilidade internacional dos estudantes de graduação, no tocante ao desenvolvimento de projetos de pesquisa, estudos, treinamento e capacitações em instituições no exterior. 0 terceiro, contribuir para o processo de internacionalização das instituições de ensino e pesquisa brasileiros. O quarto, contribuir com o aperfeiçoamento linguístico dos alunos das instituições de educação superior brasileiras. 0 quinto e último, ampliar a oferta de vagas dos centros de línguas das instituições de ensino superior possibilitando o desenvolvimento destes.

Tomando por base esses objetivos, entendemos que o programa se lança na empreitada de dar formação em língua inglesa independente da localidade para a qual o estudante pretenda se inscrever. Levando tal fato em consideração, compreendemos a noção de variação linguística deveria fazer parte do conteúdo programático abordado durante a formação desse aluno, pelo menos quanto aos quesitos geográficos e estilísticos. De acordo com a variação diatópica, as línguas variam de acordo com a localidade onde elas são faladas, então o programa IsF deveria procurar expor os alunos às diferentes variantes desse aspecto, para que ele possa escolher, dependendo da localidade da instituição na qual pretende estudar, qual a variante mais adequada para aquele país. Levando em consideração a variação diafásica, as línguas variam de acordo com os estilos de uso, e o aluno que possui esse conhecimento, muitas vezes já automatizado na sua língua nativa, precisa ter informação acerca dessas variantes para que possa utilizar a língua de modo adequado no país onde pretende fazer boa parte de sua graduação.

Com base nos objetivos expostos anteriormente, o programa IsF se propõe a executar ações para atingir três aspectos: a aplicação de testes de nivelamento e proficiência, o curso online e o curso presencial. 
A aplicação de testes de nivelamento e proficiência é feita através do TOEFL ITP, que busca não só avaliar o nível de proficiência em que os alunos se encontram, mas também funcionar como forma de acesso aos cursos presenciais desenvolvidos pelo IsF, e ajudar o núcleo gestor a estabelecer estratégias para o desenvolvimento linguístico no Brasil. O TOEFL ITP ainda serve, em algumas universidades anglófonas parceiras do programa Ciência sem Fronteiras, como comprovante do nível de proficiência dos alunos.

O curso online, (MEO) My English Online (2015), é oferecido desde os níveis mais básicos de conhecimento em língua inglesa, e é dividido em cinco níveis de ensino, cada nível com três partes. Ao fim de cada um deles, o aluno recebe uma certificação de conclusão daquela etapa.

Os cursos presenciais são desenvolvidos em núcleos em 63 universidades federais 3 . Os cursos são ministrados por graduandos do curso de Licenciatura em Letras e visam desenvolver habilidades de comunicação oral e escrita, bem como o conhecimento de culturas acadêmicas em países que utilizam a língua inglesa no ensino superior.

Em relação às ações, entendemos que o ensino da variação linguística pode ser muito bem trabalhado em sala de aula presencial ou online, de modo que o professor pudesse conhecer o nível linguístico do aluno e inserir o ensino da variação levando em consideração esse conhecimento. Desse modo, ele, o professor, trabalharia não só pontualmente, mas preferivelmente, de maneira transversal, perpassando vários tópicos ao longo dos vários níveis de conhecimento abordados.

Para entender melhor como o programa IsF está estruturado atualmente e quais são as ações que são efetivamente conduzidas pelo núcleo, conduzimos uma entrevista com um dos coordenadores do núcleo IsF da Universidade Federal da Paraíba.

\footnotetext{
${ }^{3}$ Dados de Janeiro de 2015.
} 
De acordo com o Coordenador do Programa, o IsF começou com o objetivo de capacitar alunos de graduação para participarem do Ciências sem Fronteiras, mas atualmente esse objetivo foi expandido, junto com o programa, que agora conta com outros idiomas além do inglês, e por isso há o programa Idiomas sem Fronteiras. Dentro dos novos objetivos, está a capacitação linguística para a internacionalização acadêmica do país, ou seja, capacitar as pessoas do meio acadêmico para se comunicarem com parceiros de outras universidades estrangeiras. Ou seja, o objetivo do programa hoje em dia não se volta somente para enviar alunos para o exterior, mas também para promover um maior diálogo entre as universidades brasileiras $\mathrm{e}$ as universidades estrangeiras.

Dentro desse objetivo, os alunos de inglês ainda constituem o maior número, mas, dependendo de outras universidades há diferentes núcleos, que visam o ensino de outras línguas como o alemão, o espanhol e o francês, por exemplo. Em relação ao Francês, o coordenador entrevistado relatou que eles estão atualmente numa etapa inicial, semelhante àquela que ocorreu com o (MEO), ou seja, os alunos de Francês estão participando de cursos online em parceria com a Aliança Francesa, e as universidades estão se organizando para terem núcleos das diferentes línguas contempladas pelo programa.

Sobre os cursos presenciais do IsF, foi relatado que, a princípio, eles eram voltados exclusivamente para alunos de graduação, com ênfase nos alunos dos cursos contemplados pelo Ciências sem Fronteiras, mas que, posteriormente, decidiu-se abrir a oferta de aulas presenciais para todos os cursos. Mais recentemente, essa oferta foi estendida para professores e funcionários técnico-administrativos das Instituições de Ensino Superior (IES).

Dentre as ações desenvolvidas atualmente, além de cursos presenciais que variam de 16, 32 e 48 horas, o programa faz frequentemente aplicações do TOEFL ITP, que servem como meio de acesso para os cursos presenciais. Além 
disso, ainda são oferecidos para o público minicursos sobre temas variados. Para os professores do curso, o núcleo também conta com ações voltadas para o desenvolvimento de suas capacidades enquanto professores. Para isto, os professores passam por acompanhamento constante com um dos coordenadores do curso, bem como há momentos para compartilhamento de planos de aula, e até mesmo há um momento específico em que os professores estão aprendendo a criar um curso desde sua etapa inicial, passando por etapas como elaboração dos objetivos do curso, do material didático, da forma de avaliação, entre outras. Uma ação que o núcleo do IsF da UFPB também promove é um encontro voltado pra professores de língua inglesa de escolas públicas, privadas e de cursos de idioma. Nesse encontro, há apresentação de palestras, workshops, e painéis.

Sobre o ensino de variação linguística dentro das aulas presenciais do IsF, o coordenador relata que há sim uma preocupação em abordar este tema. Para ele, em alguns momentos de feedback para alguns planos de aula, foi percebida a necessidade de abordar temas que tratassem de outras variedades do inglês e não tratassem somente do inglês americano e ou britânico, bem como de se reconhecer a validade, a importância e a relevância de outras variantes que não seja apenas a padrão. Partindo deste ponto, o coordenador relatou que os próprios professores do núcleo posteriormente propuseram uma atividade que trabalhava com gírias em inglês, porém de diferentes partes do globo, para, com isso, fomentar que há realmente variações linguísticas no uso cotidiano da língua.

\section{Análise das Entrevistas}

Esta seção tem por objetivo analisar as respostas dadas pelas duas professoras do Programa Inglês sem Fronteiras, durante a entrevista semiestruturada, conduzida a partir de três eixos: primeiramente, sobre as 
concepções acerca da variação linguística; segundo, sobre a importância da abordagem da variação linguística no ensino de inglês como língua estrangeira; e, por último, como a variação linguística é abordada nas aulas do referido Programa. É importante ressaltar que a pesquisa relatada neste texto foi submetida ao Comitê de Ética e Pesquisa da Universidade Federal da Paraíba, e aprovada por unanimidade, através do número de protocolo CAAE 53604916.7.0000.5188.

A primeira pergunta feita tinha por objetivo saber qual a concepção de variação linguística que as professoras traziam consigo. Neste momento, é importante salientar que, embora estejam atuando como professoras do programa Inglês sem Fronteiras, as entrevistadas são alunas do segundo período do curso de graduação em Letras, habilitação Língua Inglesa, pela Universidade Federal da Paraíba. Conhecer essa situação certamente contribui para a análise das respostas dadas por essas professoras, conforme veremos na respostada da Professora 1, a seguir:

Professora 1: Eu acho que é como a língua varia de acordo com as regiões, os... Lugares...

Nesta resposta, podemos ver que há uma noção de que a língua pode variar de acordo com o local onde a língua é falada, o que configuraria a variação diatópica. Essa visão é um pouco mais ampliada na fala da Professora 2:

Professora 2: (Variação linguística é) A habilidade das pessoas pronunciarem... não só palavras, mas contextos e maneiras diferentes... Como assim pronunciar contextos, né? expressar o que elas pensam e o que elas entendem, o que elas sentem de maneira diferente, com grupos de palavras diferentes. 
Há, na fala dessa professora, uma preocupação com o contexto em que a comunicação ocorre. Esse contexto seria algo que determinaria a forma como o falante escolheria qual o grupo mais adequado de palavras a serem utilizados no contexto y ou z. Apesar de falar sobre contextos distintos, o que poderia caracterizar uma variação do tipo diafásica, essa definição não entra na discussão dos tipos de variação, seja diatópica ou diastrática.

A segunda pergunta objetivou verificar a percepção das professoras acerca da importância de se ensinar ou não variação linguística em sala de aula. De modo geral, as professoras consideram que é importante ensinar diferentes variantes em sala de aula, especialmente no tocante à variação diatópica, ou seja, o ensino de vocabulário utilizado em diferentes países que utilizam língua inglesa. Vejamos o que diz a Professora 1:

Professora 1: Ok. (pausa) Sim... Sim, porque quando... quando a gente... se a gente for parar pra pensar aqui no Brasil, quando a gente sai do Nordeste talvez a gente se encontre meio perdido, e... na aula de inglês, assim... visando uma viagem internacional, né?! Acho que é importante também porque... nem sempre o que a gente aprende é o... é o que a gente vai encontrar no... aonde a gente tá indo... Nas aulas do Inglês sem Fronteiras a gente ensina 0 vocabulário bem... diversificado.

Podemos observar que a importância dada pela Professora 1 ao ensino da variação linguística é decorrente da necessidade de uso da língua pelo falante. Para explicar essa importância, ela parte de uma situação do cotidiano que pode ocorrer no Brasil, quando se sai de uma região para outra do país. Para a Professora 1, falantes de português podem sentir que uma diferença de vocabulário é suficiente para causar uma falha no entendimento. Nesse sentido, para ela, em uma viagem internacional, o uso do léxico é algo percebido como importante de ser ensinado de forma diversificada, o que caracterizaria a variação linguística, segundo a referida professora. 
A Professora 2 também ressalta a importância de se ensinar diferentes variantes nas aulas de língua inglesa, bem como diferentes sentidos que podem ser associados a referentes diferentes, de acordo com o local onde eles são pronunciados. Vejamos o que diz:

Professora 2: Sim... Sim, porque não existe uma língua inglesa. Não posso... Ah, eu ensino inglês... Tá, norte americano? Canadense? É... o chamado agora inglês internacional? Britânico? Então, existe um universo. Se eu não abordar o pouco que eu conheço desse universo, se eu não expuser isso pros meus alunos, como é que eles vão aprender a língua? Tá, eles podem entender que, por exemplo, "thong" é... um fio-dental... no português. Mas isso é pro inglês norte americano, ou até pro inglês britânico. "Thong" na Austrália é um par de chinelo, uma Havaiana. Então se eu não expuser isso pro meu aluno, que tem essa variação, como é que ele aprender, como é que ele vai conseguir se comunicar de maneira mais eficaz?

A Professora 2 ressalta a importância do ensino da variação na língua inglesa, especialmente quando afirma que "não há uma língua inglesa" (grifo nosso) e, para demonstrar tal fato, explica que há diferentes variedades do inglês, e ainda elenca os países onde o idioma é falado. Além disso, a Professora 2 demonstra a necessidade de explicar aos alunos do Programa os diferentes sentidos que um vocábulo pode assumir a depender da localização na qual ele é pronunciado.

A terceira pergunta teve como objetivo verificar se essas professoras ensinam a variação linguística nas aulas do Programa e de que maneira isso acontece. Em geral, as respostas das professoras se assemelham no que diz respeito ao modo como a variação linguística é abordada nos cursos do Inglês sem Fronteiras. Tal fato certamente decorre de os planos de aula do Programa serem compartilhados, conforme nos relatou a Professora 1:

Professora 1: Sim a gente... Como os planos são... são compartilhados, aí a gente... cada um... é... trabalha ele do jeito que acha melhor com sua turma né?!... adapta. Aí... é, nos planos da gente, a gente trabalha bem a variação, 
assim, eu acho que a gente... trabalha o vocabulário de diversas partes do... de diversos países falantes de língua inglesa, e principalmente no curso em foco, que... a gente mostra mesmo, assim tem lugar que "traffic signal" é chamado assim, e... na África do sul é chamado de "robot", e coisas bem... diferentes assim.

A resposta dada pela Professora 1 revela semelhanças com a resposta dada pela Professora 2 no tocante a considerar como as variações de uso do léxico em relação ao países onde se fala o inglês. Merece destaque o fato de haver uma prática de compartilhamento de planos de aula por parte dos professores do Programa, o que favorece para que o tema "variação linguística" seja abordado por uma grande quantidade de professores, e, assim, possa ser melhor compreendido por vários alunos.

Já a Professora 2 refere-se à sua prática docente no tocante ao ensino da variação linguística da seguinte maneira:

Professora 2: Eu gosto de pensar que sim, mas assim, considerando que eu não tenho todo esse respaldo teórico, né?! pra falar a respeito da variação linguística, mas eu abordo... dessa maneira como eu falei, o pouco que eu conheço se eu sei que uma palavra pode ser pronunciada de três maneiras diferentes eu vou apresentar essas três maneiras diferentes. Eu vou... trabalhar... pronúncia com os alunos de modo que a comunicação seja fluida, que ela aconteça... mas eles podem escolher o chamado "sotaque" que eles quiserem, e... eu costumo apresentar assim... é, o pouco que eu sei, eu vou te dar um exemplo bem simples. É... A maneira de falar "oi". A gente sabe que tem o "Hi", "Hello", aí tem o "What's up?" que é já mais gíria, tem o "Howdy", que é específico dos vaqueiros norte americanos, então é uma variação linguística, existe. Eu sei lá se um dia meu aluno vai viajar pro Texas, vai que de repente ele (pausa) "vou morar seis meses no Texas", ele vai usar, ele vai ouvir "Howdy" e ele não vai saber o que é que é. Mas se ele passar por mim ele já vai ter uma noçãozinha. Então assim, o pouco que eu sei eu vou passando e espero que ajude eles de alguma maneira.

Nesta resposta, podemos perceber que há uma preocupação por parte da professora em não somente ensinar diferentes formas de uso da língua de acordo com o país onde o inglês é falado, mas também em mostrar diferentes 
pronúncias. A professora revela, ainda, a importância de o professor ter uma compreensão teórica acerca da variação linguística que fundamente a prática do professor em sala de aula. Nesse sentido, faz questão de destacar que não tem o "respaldo teórico" suficiente para dar conta dessa abordagem na sala de aula, mas que, dentro dos limites que possui, preocupa-se em repassar o que conhece para seus alunos de forma que eles consigam utilizar a língua de forma mais efetiva.

De modo geral, a análise das respostas dadas pelas Professoras 1 e 2 revela que, embora demonstrem (no caso da Professora 1, ela também reconhece) não ter uma fundamentação teórica acerca da concepção de variação linguística e de seus tipos que subsidie suas práticas de sala de aula, há uma preocupação por parte dessas professoras em ensinar a língua inglesa sem considerá-la uma língua imutável e invariável, deixando, assim, de reproduzir um discurso que preconiza o ensino da gramática normativa.

Esta visão entra vai de encontro ao que é exposto por Alves e Battisti (2014), quando do desenvolvimento do projeto com alunos de Letras-Inglês da UFRGS, conforme contextualizado anteriormente. Esses autores relataram que os alunos tinham conhecimento teórico sobre a Sociolinguística, mas não tinham conhecimento de ordem prática; fato contrário ao apresentado pelas professoras do Programa Idioma Sem Fronteiras, que também são alunas do curso de Letras-Inglês da UFPB. Por outro lado, os alunos participantes do projeto dos referidos autores reproduziram a ideia de uma língua ideal, preconizada nos manuais, a qual os falantes não nativos devem se adequar. Já as Professoras 1 e 2, entrevistadas para esta pesquisa, demonstraram ser relevante mostrar como o uso que se pode fazer do inglês no cotidiano, do ponto de vista oral, e não se prender ao que é preconizado pelos manuais de ensino de dessa língua. 
Talvez o fato de essas alunas já estarem atuando em sala de aula, na condição de professoras, contribua para que elas possam atribuir um valor positivo ao ensino da variação linguística aos seus alunos, extrapolando assim o ensino para além daquilo que é ditado pela gramática normativa.

Do mesmo modo que Alves e Battisti (2014) apontam a necessidade de se fazer mudar a concepção dos alunos, futuros professores de inglês como segunda língua, no que diz respeito ao ensino da variação linguística na escola, tendo, para isso, desenvolvido o projeto em tela entendemos que esta pesquisa poderá contribuir no sentido de se verificar a importância de o professor estar devidamente fundamentado teoricamente acerca das noções da Sociolinguística para que possa desenvolver um trabalho ainda melhor na sua prática de ensino, uma vez que poderá fazer a articulação entre a teoria e a prática.

\section{Considerações Finais}

Este trabalho buscou investigar os relatos sobre o ensino da variação linguística dentro do programa Inglês sem Fronteiras. Para isto, iniciamos caracterizando a língua inglesa dentro do cenário internacional e investigamos uma concepção de língua que comportasse o estudo da variação linguística, bem como de uma abordagem de ensino de línguas estrangeiras que levasse a variação linguística em consideração entre seus pressupostos. Desta forma, a Sociolinguística variacionista foi a corrente teórica que melhor apresentou uma concepção de língua para aquilo a que nos propomos, bem como a Abordagem Comunicativa foi a abordagem de ensino de línguas estrangeiras que abarcou as variações que ocorrem na língua dentro de uma das competências que precisam ser trabalhadas para que o aluno consiga atingir uma chamada competência comunicativa, e assim se expressar da melhor maneira em contextos reais. 
Em seguida, apresentamos relatos sobre como essa variação linguística foi abordada em quatro estudos distintos, com objetos de estudo por vezes diferentes. Nesses estudos, pudemos ver que não somente a variação linguística é pouco explorada nos manuais didáticos, e quando é tratada é a título de curiosidade ou ainda como um detalhe superficial, que não tem relação com a forma da língua funcionar cotidianamente, mas também os professores de língua inglesa, ou ainda, os futuros professores, veem que a variação é algo que não compete ao aluno de inglês como língua estrangeira, sendo restrita apenas ao falante nativo. Esta visão hermética, inclusive, descarta a possibilidade de um aluno ter contato com falantes nativos, ou ainda com materiais que exploram essas variações.

Posteriormente, procuramos caracterizar o programa Inglês sem Fronteiras desde sua criação, abarcando as ações promovidas em âmbito nacional, como o My English Online, e em âmbito local, as principais ações de aplicação de testes de proficiência (TOEFL ITP) e as aulas presenciais realizadas dentro de núcleos nas Instituições de Ensino Superior. Também procuramos caracterizar este programa em sua atualidade, através de dados fornecidos por um dos coordenadores do programa na UFPB. A partir destes dados, vimos que o programa, que a princípio se voltava para capacitar alunos de graduação para participarem do programa Ciências sem Fronteiras, hoje adquire um objetivo mais amplo e com visão mais duradoura, que é capacitar não somente alunos, mas também professores e funcionários técnico-administrativos das IES para promover uma internacionalização das universidades públicas, de modo a capacitar todos aqueles com vínculo nas universidades a se comunicarem em língua estrangeira, visando estreitar laços com instituições de outros países.

Em relação ao relato das professoras do programa Inglês sem Fronteiras, foi possível perceber que há um conhecimento tácito sobre o que vem a ser a variação linguística. As professoras demonstraram através de exemplos que 
possuem noção de que trata este fenômeno, apesar de não possuírem amplo conhecimento a respeito, e reconhecerem essa falta de conhecimento, para se aprofundar nos tipos de variação que por ventura possam existir.

Em seguida, constatamos que as professoras consideram que é importante abordar o ensino da variação linguística durante suas aulas, e o fazem justificando a diferença de vocabulário que existe dentro da língua inglesa, bem como reconhecendo que não há uma língua inglesa única, padronizada, idêntica para todos os falantes.

Finalmente, buscamos verificar no discurso das professoras se elas abordavam o ensino de variação linguística em sala de aula. É interessante ver como os discursos delas se assemelham em relação ao que é praticado dentro das aulas do IsF. As duas professoras mostraram preocupação em levar para sala de aula exemplos de como a língua inglesa é variável.

Com este trabalho, procuramos mostrar a importância do ensino da variação linguística, em especial consideramos que vivemos numa sociedade em que o acesso à informação das mais variadas fontes é facilitada pelo uso da internet, em especial devido à popularização dos dispositivos móveis. E, devido a esta grande quantidade de informações, algumas podem chegar aos aprendizes de línguas estrangeiras como erros, se a visão de uma língua imutável for a preconizada. Um exemplo é o uso de inglês afro-americano ${ }^{4}$, tão presente nas músicas que nos chegam através das rádios e da internet, por exemplo.

Outro tópico que merece atenção dentro da sala de aula de língua inglesa, bem como de outros idiomas de grande alcance mundial, é a escolha de uma variação dialetal pelo professor. Atualmente, na Linguística, não se considera que uma forma seja superior a outra, apesar de historicamente algumas terem mais prestígio que outras. Em sala, o professor precisa ser

\footnotetext{
${ }^{4}$ Para mais detalhes, ver African American Vernacular English is not Standard English with Mistakes, de Geoffrey K. Pullum (1999).
} 
consistente em sua escolha, sem ficar alternando entre uma forma e outra. A inconsistência por parte do professor pode levar o aluno a uma confusão, pensando que algumas variantes podem ser intercambiáveis, o que pode não acontecer na língua efetivamente falada.

Finalmente, é importante que a variação linguística seja efetivamente trabalhada no ensino de inglês como língua estrangeira, para que o aluno possa desenvolver sua competência comunicativa como um todo, bem como para quebrar a ideia de uma língua homogênea e imutável, de uma língua ideal. É preciso que professor e aluno vejam que as diferenças existentes nas variáveis não são apenas formas diferentes, mas que são formas igualmente válidas e ricas dentro da língua.

\section{Referências}

ALVES, Ubiratã Kickhöfel; BATTISTI, Elisa. Variação e diversidade linguística no ensino-aprendizagem de língua inglesa na graduação em letras. Cadernos de Letras da UFF, Niterói, n. 48, p. 291-311, 2014.

BELINE, Ronald. A variação linguística. In: FIORIN, José Luiz (Org.). Introdução à linguística: objetos teóricos. 6. ed. São Paulo: Contexto, 2012. p. 121-140.

BORTONI-RICARDO, Stella M. Nós cheguemu na escola, e agora? Sociolinguística \& educação. São Paulo: Parábola, 2005.

BRASIL. Ministério da Educação. Idiomas Sem Fronteiras. Inglês: curso presencial. Disponível em: <http://isf.mec.gov.br/ingles/pt-br/cursopresencial>. Acesso em: 6 set. 2015a.

BRASIL. Ministério da Educação. Idiomas Sem Fronteiras. Inglês: teste de nivelamento. Disponível em: <http://isf.mec.gov.br/ingles/pt-br/testes-denivelamento>. Acesso em: 6 set. 2015b.

BRASIL. Ministério da Educação. Portaria n. 1.466, de 18 de dezembro de 2012. Institui o Programa Inglês sem Fronteiras. 2012. Disponível em: 
<http://www.cmconsultoria.com.br/imagens/diretorios/diretorio16/arquivo4359 .pdf>. Acesso em: 6 set. 2015.

BRASIL. Presidência da República. Decreto n. 7.642, de 13 de dezembro de 2011. Institui o Programa Ciências sem Fronteiras. 2011. Disponível em:

<http://www.planalto.gov.br/ccivil_03/_Ato2011-

2014/2011/Decreto/D7642.htm>. Acesso em: 6 set. 2015.

BROWN, Douglas. Teaching by principles: an interactive approach to language teaching. 2. ed. White Plains: Longman, 2001.

CHOMSKY, Noam. Conceitos de língua. In: O conhecimento da Língua: sua natureza, origem e uso. Alfragide: Caminho, 1994. p. 35-65.

FALCÃO, Cristiane Vieira; SILVA, Ewerton Felix. As variantes da Língua Inglesa em sala de aula: uma abordagem didático-pedagógica. In: ENCONTRO DE INICIAÇÃO À DOCÊNCIA DA UEPB, 3., 2013, Campina Grande. Anais... Campina Grande: ENID/UEPB: Realize, 2013. v. 1, n. 1.

FRANÇA, Valéria. Do you speak...? Veja educação, 2001. Disponível em: <http://veja.abril.com.br/idade/educacao/140896/p_062.html>. Acesso em: 1 jun. 2015.

FRANCESCON, Paula Kracker; SENEFONTE, Fábio Henrique Rosa; BARONAS, Joyce Elaine de Almeida. Variação linguística no ensino de língua inglesa. Revista Entrelinhas, São Leopoldo, v. 7, n. 2, p. 209-221, jul./dez., 2013.

LYONS, John. Linguagem. In: LYONS, John. Linguagem e linguística: uma introdução. Rio de Janeiro: LTC, 1987. p. 1-23.

MANZINI, Eduardo José. Considerações sobre a elaboração de roteiro para entrevista semi-estruturada. In: MARQUEZINE, Maria Cristina; ALMEIDA, Maria Amélia; OMOTE, Sadao (Org.). Colóquios sobre pesquisa em educação especial. Londrina: EDUEL, 2003. p. 11-25.

MULLER, Fernanda Suely. Introdução à história e cultura dos povos de língua inglesa. In: CLAUDINO, Barthyra Cabral Vieira de Andrade (Org.). Inglês. curso de licenciatura em letras-língua inglesa a distância. João Pessoa: Ed. da UFPB, 2014. p. 170-173.

MY ENGLISH ONLINE. Disponível em: <http://www.myenglishonline.com.br/ saiba-mais>. Acesso em: 6 set. 2015. 
PULLUM, Geoffrey K. African American vernacular English is not Standard English with mistakes. In: WHEELER, Rebecca. The workings of language: from prescriptions to perspectives. 1999. p. 59-66.

RODRIGUES, Daniel de Sá. O tratamento da variação linguística em livros didáticos de Língua inglesa. 2005. 82f. Dissertação (Mestrado em Linguística Aplicada) - Universidade Estadual do Ceará, Fortaleza.

SAUSSURE, Ferdinand. Curso de linguística geral. Tradução de Antônio Chelini, José Paulo Paes e Izidoro Blikstein. 34. ed. São Paulo: Cultrix, 2012.

SAVIGNON, Sandra J. Communicative language teaching for the twenty-first century. In: CELSE-MURCIA, Marianne (Org.). Teaching English as a second or foreign language. 3. ed. Londres: Heinle \& Heinle Thomson Learning, 2001. p. 13-28. 